International Journal of Current Advanced Research

ISSN: O: 2319-6475, ISSN: P: 2319 - 6505, Impact Factor: SJIF: 5.995

Available Online at www.journalijcar.org

Volume 6; Issue 3; March 2017; Page No. 2819-2821

DOI: http://dx.doi.org/10.24327/ijcar.2017.2821.0115

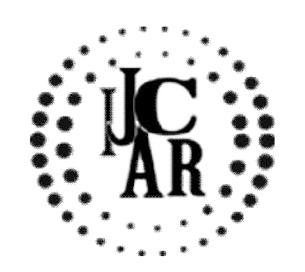

Research Article

\title{
ENDODONTIC MANAGEMENT HOT TOOTH IN CLINICAL PRACTICE -A QUESTIONAIRRE SURVEY
}

\section{Thanish Ahamed S and Jayalakshmi}

Department of Conservative Endodontics, Saveetha Dental College.

\section{A R T I C L E I N F O}

\section{Article History:}

Received $19^{\text {th }}$ December, 2016

Received in revised form $16^{\text {th }}$ January, 2017

Accepted $26^{\text {th }}$ February, 2017

Published online $28^{\text {th }}$ March, 2017

\section{Key words:}

Hot Tooth, Endodontic Management

\begin{abstract}
A B S T R A C T
Aim: To know the Knowledge, Attitude and Practices regarding the management of HOT TOOTH by clinicians and PG students.

Background: The term "hot" tooth generally refers to a pulp that has been diag- nosed with irreversible pulpitis, with spontaneous, moderate-to-severe pain. The main challenge in the management of hot tooth is that it can't be easily anaesthetised. Various strategies are used
\end{abstract} to over come this.

Reason: The survey is done to assess the Knowledge, Attitude and Practices of clinicians and PG students.

Copyright $\bigcirc 2017$ Thanish Ahamed $\boldsymbol{S}$ and Jayalakshmi. This is an open access article distributed under the Creative Commons Attribution License, which permits unrestricted use, distribution, and reproduction in any medium, provided the original work is properly cited.

\section{INTRODUCTION}

In 20th century the world is witnessing many revolution in the medical treatment and care. Even though there is increased medication which has a high success rate, there are some criteria where the medication may fail. One such criteria is the HOT TOOTH which is nothing but irreversible pulpitis ${ }^{[1,2]}$. The term "hot" tooth generally refers to a pulp that has been diag- nosed with irreversible pulpitis, with spontaneous, moderate-to-severe pain ${ }^{[3,4]}$. The main challenge in the management of hot tooth is that it can't be easily anaesthetised easily.

Pulpitis is inflammation of the dental pulp resulting from untreated caries, trauma, or multiple restorations. There are classified as two types. Reversible and irreversible pulpitis ${ }^{[5-}$ ${ }^{7]}$. Irreversible pulpitis is a clinical condition characterised by the inflammation of the pulp. This condition stems from a variety of predisposing factors, including: reversible pulpitis, pulpal damage during operative procedures, or reduced pulpal blood flow due to trauma or orthodontic movement.The main reason for the anaesthetic failure is the Activation of nociceptors in the presence of inflammation. To over come this there are lot of strategy are used ${ }^{[8,9]}$. Recent research have provide various new strategy to over come this anaesthetic failure ${ }^{[14,15]}$. The main aim of the dental practitioner is to provide proper diagnosis and treatment and make the patient

\section{*Corresponding author: Thanish Ahamed S}

Department of Conservative Endodontics, Saveetha Dental College. free from illness. So as a dentist they must have knowledge about the hot tooth and they must know the management strategies for the anaesthetic failure of the tooth ${ }^{[10]}$. This research is done to asses the knowledge, attitude and practices of clinicians and PG students about the management of hot tooth.

\section{MATERIALS AND METHODS}

The participant of the study includes clinicians and post graduate students. A generalised questioner was prepared and they were asked to fill. There were 10 open ended question in the questionnaire. The participants were asked to answer all the questions to access them. About 200 participants actively participated in the survey. Out of 200 participants 133 $(66.5 \%)$ are clinicians and $67(33.5 \%)$ are post graduated students. The questionnaire contain questions such as reason for anaesthetic failure, there management, the tooth which is more difficult to anaesthetise and many other questions.

\section{According to the collected data}

Question 1 Participants

\begin{tabular}{ccc}
\hline & Frequency & Percentage \\
\hline Clinicians & 133 & $65.5 \%$ \\
Post graduates & 67 & $33.5 \%$ \\
\hline
\end{tabular}

Question 2 Awareness about hot tooth

\begin{tabular}{ccc}
\hline & Frequency & Percentage \\
\hline Aware & 152 & $76 \%$ \\
Unaware & 48 & $24 \%$ \\
\hline
\end{tabular}


Question 3 knowledge about hot tooth

\begin{tabular}{ccc}
\hline & Frequency & Percentage \\
\hline Reversiblepulpitis & 48 & $24 \%$ \\
Irreversible pulpitis & 116 & $58 \%$ \\
Other endodontic treatment & 22 & $22 \%$ \\
\hline
\end{tabular}

Question 4 Main challenge in hot tooth

\begin{tabular}{ccc}
\hline & Frequency & Percentage \\
\hline Cannot be identified easily & 56 & $28 \%$ \\
Cannot be anaesthetised easily & 108 & $54 \%$ \\
Cannot be treated & 36 & $18 \%$ \\
\hline
\end{tabular}

Question 5 Reason for anaesthetic failure

\begin{tabular}{ccc}
\hline & Frequency & Percentage \\
\hline Activation of noiciceptor & 22 & $44 \%$ \\
Tooth cannot be identified & 20 & $40 \%$ \\
Wrong placement of injunction & 3 & $6 \%$ \\
Requires high doasage & 5 & $10 \%$ \\
\hline
\end{tabular}

Question 6 The most difficult tooth to be anaesthetised

\begin{tabular}{ccc}
\hline & Frequency & Percentage \\
\hline Maxillary anteriors & 32 & $16 \%$ \\
Maxillary premolars & 52 & $26 \%$ \\
Mandibular molar & 92 & $46 \%$ \\
Mandibular anteriors & 24 & $12 \%$ \\
\hline
\end{tabular}

Question 7 preferred technique after the failure of IANB

\begin{tabular}{ccc}
\hline & Frequency & Percentage \\
\hline Intra pupal injection & 64 & $32 \%$ \\
Intra ligamental injection & 56 & $28 \%$ \\
Mental nerve block & 28 & $14 \%$ \\
Any of these & 52 & $26 \%$ \\
\hline
\end{tabular}

Question 8 Prescribed medication if debridement is not possible

\begin{tabular}{ccc}
\hline & Frequency & Percentage \\
\hline Strong analgesic & 52 & $26 \%$ \\
Penicillins & 56 & $28 \%$ \\
NSAIDS & 64 & $32 \%$ \\
None of the above & 28 & $14 \%$ \\
\hline
\end{tabular}

Question 9 Preferred technique to block inferior alveolar nerve

\begin{tabular}{ccc}
\hline & Frequency & Percentage \\
\hline Inferior alveolar nerve block & 80 & $40 \%$ \\
Gow gates technique & 60 & $30 \%$ \\
Vaziraniakinosis & 36 & $18 \%$ \\
Otheir technique & 24 & $12 \%$ \\
\hline
\end{tabular}

Question 10 Most preferred anaesthetic agent

\begin{tabular}{ccc}
\hline & Frequency & Percentage \\
\hline Mepivacaine & 32 & $16 \%$ \\
Prilocaine & 44 & $22 \%$ \\
Articaine & 20 & $10 \%$ \\
Lidocaine & 104 & $52 \%$ \\
\hline
\end{tabular}

Question 11 Strategy used to improve the success of IANB

\begin{tabular}{ccc}
\hline & Frequency & Percentage \\
\hline Placebo & 48 & $24 \%$ \\
Oral medication & 64 & $32 \%$ \\
High dose of anaesthetics & 60 & $30 \%$ \\
Others & 28 & $14 \%$ \\
\hline
\end{tabular}

\section{RESULTS}

From the above tabulation we found that approximately $76 \%$ of the participants are aware about hot tooth and $24 \%$ of the participants are unaware of hot tooth.
Out of 200 participants, majority of $58 \%$ defines hot tooth as irreversible pulpitis and $24 \%$ says as reversible pulpitis and the remaining $22 \%$ says them as other endodontic treatment. The main challenge reported by $54 \%$ in hot tooth management is the tooth cannot be easily anaesthetised and $28 \%$ says it cannot be identified easily and the rest $18 \%$ says that the hot tooth can not be treated easily. $44 \%$ of the participants says that the anaesthetic failure is due to the activation of nociceptor at the site inflammation and $40 \%$ says that the anaesthetic failure is due to the lack of identification of the tooth and the remaining $10 \%$ says that it requires high dosage of anaesthetic and the rest $6 \%$ says it's due to wrong placement of injection.

Majority of the participants $46 \%$ says that Mandibular molars are difficult to anaesthetised and $26 \%$ says that maxillary premolars and $16 \%$ says maxillary anteriors is difficult and the rest $12 \%$ says Mandibular anteriors. The preferred technique handled after the failure of IANB is intra pupal injection said by $32 \%$ and $28 \%$ prefers intra ligamental injection and $14 \%$ prefers mental nerve block and the rest $26 \%$ doesn't prefers any of these technique. The prescribed medication if the debridement is not possible, the majority of $32 \%$ prescribe NSAIDS and $26 \%$ prescribe strong analgesic and $28 \%$ prescribes penicillins and the remaining $14 \%$ prescribe some other medication. The preferred technique for blocking the inferior alveolar nerve are inferior alveolar nerve block by $40 \%$, Gow gates technique by $30 \%$ and vaziraniakinosis by $18 \%$ and other technique by $12 \%$.

The most preferred anaesthetic agent from the most to least are as follows lidocaine followed by Prilocaine followed you Mepivacaine and the least is Articaine. 32\% says that oral medication can improve the success rate and 30\% says that increasing the dosage of anaesthetic can improve the anaesthetic failure and $24 \%$ prescribe placebo and the remaining $14 \%$ prefer other technique.

\section{DISCUSSION}

Above results says that awareness among hot tooth have showed marked increased in the clinicians and post graduate students when compared to previous studies. The knowledge about the hot tooth is also likely increased among them. While considering about the main challenge only 54\% were correctly able to identify that the tooth cannot be easily anaesthetised and remains of $28 \%$ said it cannot be identified easily, so it's is quite low. Knowledge about the anaesthetic failure is in a very close margin. There is a difference of about $4 \%$ between the activation of nociceptor and difficulty in identifying the tooth, the former leads the table.

Many research [1] says that Gow gates technique is very successful in case of hot tooth but this research says that the participants mostly prefer inferior alveolar nerve block over the Gow gates technique and the other supplementary technique such as Vaziraniakinosis. Other research ${ }^{[11-13]}$ says that Oral medication can improve the success rate of anaesthetic failure but only $32 \%$ have correctly identified this.

\section{RESULTS}

The results says that clinicians and post graduate students are aware about hot tooth but they lack knowledge in the management of hot tooth. The aim of the dentist is to provide relief and to do proper treatment. So various conferences and 
CMI programs should be conducted to make the practitioners to over come the management problem of hot tooth. Hence, the clinician should have fall back strategies to attain good pulpalanesthesia when failures of the traditional techniques are encountered. This will boost the confidence of the clinician to impart and provide a relatively pain free treatment for the patients having a hot tooth

\section{Reference}

1. Nusstein JM, Reader A, Drum M. Local anesthesia strategies for the patient with a 'hot' 'tooth. Dent Clin North Am 2010; 54:237-47

2. S, Burns RC, editors: Pathways of the Pulp, 10th ed., Mosby, St. Louis, pp 696-713

3. Nusstein J, Reader A, Nist R, Beck M, Meyers WJ. Anesthetic efficacy of the supplemental intraosseous injection of $2 \%$ lidocaine with 1:100,000 epinephrine in irreversible pulpitis. $J$ Endod 1998;24:487-91.

4. Byers M, Taylor P, Khayat B, et al. Effects of injury and inflammation on pulpal and periapical nerves. J Endod 1990;16:78-84 12. Modaresi J, Dianat O, Soluti A.

5. Effect of pulp inflammation on nerve impulse quality with or without anesthesia. 2008; 34:438-41.

6. ThangavelBoopathi, J Endod Mathew sabeena, Kailasamsivakumar, Jaya kodiharikaran, Kumaravadivel karthick, Aruna Raj. Supplimentalpulpalanesthesia for mandibular teeth. Journal of Pharmacy and Bioallied Sciences. 2013;5(Suppliment 1).

7. Reemers T, Glickman G, Spears R, He J: The efficacy of the IntraFlow intraosseous injection as a primary anesthesia technique. J Endod 34:280, 2008.
8. Sampaio, Roberta Moura, et al. "Comparison of the anesthetic efficacy between bupivacaine and lidocaine in patients with irreversible pulpitis of mandibular molar." Journal of endodontics 38.5 (2012): 594-597.

9. Aminsobhani, Mohsen, et al. "Effect of Local and Application of Amitriptyline and Imipramine on Teeth with Irreversible Pulpitis Failed PulpalAnesthesia: A Randomized, Double-blind, Controlled Trial." Dental Hypotheses 7.4 (2016): 128.

10. Parirokh, Masoud, and Paul V. Abbott. "Various strategies for pain-free root canal treatment." Iranian endodontic journal 9.1 (2013): 1-14. And

11. Abazarpoor, Ramin, et al. "A comparison of different volumes of articaine for inferior alveolar nerve block for molar teeth with symptomatic irreversible pulpitis." Journal of endodontics 41.9 (2015): 14081411.

12. Monteiro, M. R. F. P., et al. "4\% articaine buccal infiltration versus $2 \%$ lidocaine inferior alveolar nerve block for emergency root canal treatment in mandibular molars with irreversible pulpits: a randomized clinical study." International endodontic journal 48.2 (2015): 145-152.

13. Ingle JI, Bakland LK. Preparation for Endodontic Treatment. In: Endodontics. 5th ed, Hamilton (ON): BC Decker; 2002. p. 385.

14. W.B. Saunders, Philadelphia,. Carr GB: Ch. 20, Local anesthesia in endodontics. In Cohen

15. Guglielmo A, Nist R, Reader A: Palatal and buccal infiltrations in maxillary first molar anesthesia. J Dent Res 72:274 (abstract), 1993.

\section{Please cite this article in press as:}

Thanish Ahamed S and Jayalakshmi (2017), 'Endodontic Management Hot Tooth In Clinical Practice -A Questionairre Survey', International Journal of Current Advanced Research, 6(3), pp. 2819-2821.

http://dx.doi.org/10.24327/ijcar.2017.2821.0115 